\title{
ADOLESCENT QUALITY OF LIFE AND HEALTH BEHAVIORS: A COMPARATIVE STUDY BETWEEN ADOLESCENTS FROM THE SOUTH OF PORTUGAL AND SPAIN
}

\author{
Marta Lima-Serrano ${ }^{1}$, Ida Lemos², Cristina Nunes ${ }^{3}$
}

\footnotetext{
${ }^{1}$ Ph.D. in Nursing. Assistant Professor. Department of Nursing, University of Seville. Seville, Spain. E-mail: mlima@us.es

2 Ph.D. in Psychology, Assistant Professor. Research Center for Spatial and Organizational Dynamics, University of Algarve, Portugal. Faro, Algarve, Portugal. E-mail: ilemos@ualg.pt

${ }^{3}$ Ph.D. in Psychology, Associate Professor. Research Center for Spatial and Organizational Dynamics, University of Algarve, Portugal. Faro, Algarve, Portugal. E-mail: csnunes@ualg.pt
}

\begin{abstract}
An observational, transversal study was carried out to examine cross-cultural differences in perceived quality of life and health-related behaviors on adolescents from southern Portugal and southern Spain. Sample consists in 319 adolescents. The Kidscreen-27 child self-report, a short version of Health Behavior in School-aged Children Questionnaire, and a Socio-demographic questionnaire were used. Results suggest significant differences between Portuguese and Spanish adolescents health behaviors. Portuguese adolescents experiment more legal drugs and consume more wine and beer. More Spanish adolescents smoke. No differences were found between countries on hashish use, liquor consumption, inebriation, and on the age of first sexual intercourse. Spanish adolescents perceived themselves with better quality of life. Gender differences were found on several dimensions of Quality of Life. Results are discussed with previous research on these topic and might be considered by nurses when promoting adolescent health.
\end{abstract}

DESCRIPTORS: Quality of life. Behavior. Risk. Adolescents. Cross-cultural comparison.

\section{QUALIDADE DE VIDA E COMPORTAMENTOS DE SAÚDE: UM ESTUDO COMPARATIVO ENTRE ADOLESCENTES DO SUL DE PORTUGAL E DA ESPANHA}

\begin{abstract}
RESUMO: Desenvolvemos um estudo observacional, transversal para analisar eventuais diferenças na qualidade de vida percebida e em comportamentos de saúde em 319 adolescentes do sul de Portugal e do sul de Espanha. Utilizamos o Kidscreen-27, uma versão breve do "Health Behavior in School-aged Children" e um questionário sociodemográfico. Foram encontradas diferenças significativas entre os adolescentes portugueses e espanhóis nos comportamentos de saúde. Os portugueses consomem mais vinho e cerveja e experimentam mais drogas legais, os espanhóis apresentam um maior consumo de tabaco. Não foram encontradas diferenças no consumo de haxixe, e bebidas destiladas, embriaguês e idade da primeira relação sexual. Os espanhóis reportaram maiores níveis de qualidade de vida percebida. Foram encontradas diferenças de gênero em várias das suas dimensões. Os resultados são discutidos com base nos estudos prévios nestes tópicos, e podem contribuir para a prática profissional de enfermagem na promoção da saúde na adolescência.
\end{abstract}

DESCRITORES: Qualidade de vida. Comportamento. Risco. Adolescentes. Estudos transculturais.

\section{CALIDAD DE VIDA Y ESTILOS DE VIDA EN ADOLESCENTES: UN ESTUDIO COMPARATIVO ENTRE EL SUR DE ESPAÑA Y EL SUR DE PORTUGAL}

\begin{abstract}
RESUMEN: Se realizó un estudio observacional, transversal para examinar diferencias en calidad de vida percibida y estilos de vida de adolescentes del sur de Portugal y del sur de España. A 319 adolescentes, se les administró el Kidscreen-27, una versión corta del cuestionario "Health Behavior in School-aged Children", y un cuestionario sociodemográfico. Se observaron diferencias estadísticas entre adolescentes portugueses y españoles. Los portugueses experimentan más drogas legales, y consumen más vino y cerveza. Los españoles consumen más tabaco. No se encontraron diferencias entre países en el uso de hachís, bebidas destiladas, embriaguez y edad de la primera relación sexual. Los españoles se perciben con mayor calidad de vida. Se encontraron diferencias de género en varias dimensiones de la calidad de vida, principalmente entre adolescentes españoles. Se discuten los resultados con investigaciones previas sobre estos tópicos, y pueden ser considerados por las enfermeras en la promoción de salud adolescente.
\end{abstract}

DESCRIPTORES: Calidad de vida. Conducta. Riesgo. Adolescentes. Comparación transcultural. 


\section{INTRODUCTION}

Childhood and adolescence are widely considered as critical periods in human development, in which, being exposed to noxious factors frequently causes enduring effects. Health-related and social interventions at these stages of development may have positive effects in individuals. Particularly during adolescence, the adoption of unhealthy lifestyles or risk behaviors, such as substance abuse, sexual risk behaviors, and anti-social behaviors are associated with sexually transmitted diseases, teenage pregnancy, and psychopathological disorders. ${ }^{1-2}$

This assumption has certainly, in the last decade, influenced the funding of research on risk and protection factors that determine the health of adolescents. In this sense, it has been stated that the concept of health encompasses the individual's perception about his or her own life, attending cultural and contextual specificities and his/her value-system, and is related with goals, expectations, values and perspectives about welfare..$^{3-5}$ Therefore, perceived Quality of Life (QoL) can be defined as a multidimensional construct that includes one's physical health, psychological well-being, independence level, social relationships and relations with his/her environment and social context. ${ }^{1,6}$ Furthermore, QoL dimensions are influenced by variables such as gender, age, socio-economic status and culture. ${ }^{4,7}$

Perceived QoL in adolescents can be useful in identifying subgroups of children and adolescents at risk of engaging in health-compromising behaviors, and it can also assists in determining the burden of a particular disease or disability. In fact, adolescence is a vulnerable period in human development characterized by numerous bio-psycho-social changes that may influence the engagement in health-related risk behaviors. For instance, results from the Health Behaviour in School-Aged Children (HBSC) study, conducted in 2010 with adolescents aged 11 to $18^{\text {th }}$ in thirtynine countries and regions across Europe and North America, showed that, although most of adolescents reported a good health status, sizeable minorities experienced unhealthy lifestyles or enhanced risk behaviours. Moreover, $18 \%$ of 15 -year-old adolescents reported smoking at least once a week, $21 \%$ reported weekly drinking, 32\% reported been drunk at least twice and $17 \%$ of the teenagers reported using illegal drugs (cannabis) at least once in their life. Furthermore, 26\% of the 15 -year-olds adolescents reported having initia- ted sexual intercourse. Also, results of the HSBC (2010) indicated differences on health status by age group, gender, socioeconomic status country, and ethnicity. ${ }^{2}$ Concerning substance misuse, $34.8 \%$ of the participants in the Spanish HBSC (2006) had experimented tobacco, $11.3 \%$ reported weekly consumption of liqueur, and 29.1\% reported hashish consumption. With reference to sexual behavior, $34.8 \%$ of the Spanish participants reported having sexual intercourse. Specifically in Andalusia, $36.2 \%$ reported smoking, $13 \%$ indicated a weekly consumption of liqueur, $25.6 \%$ reported hashish consumption and $30.3 \%$ reported having sexual intercourse. ${ }^{9}$

In its turn, $30 \%$ of the adolescents of the Portuguese HBSC (2010) reported having tobacco consumption, $2.8 \%$ reported weekly consumption of liqueur, and $8.8 \%$ reported hashish consumption. With reference to sexual activity, $21.8 \%$ reported having sexual intercourse. In Algarve, $22.5 \%$ reported having experimented tobacco, 3.3\% having a weekly consumption of liqueur, 10.9\% having hashish consumption and $23.2 \%$ having sexual intercourse. ${ }^{10}$

As these results suggest, even if most adolescents report an overall positive engagement in these health-related behaviors, a smaller group of both Spanish and Portuguese teenagers tend to engage in risky behaviors, with implications in health and positive adjustment. ${ }^{1}$ Differences across countries and regions were found, which might be linked to different social status or specific cultural contexts. In this concern adolescents from southern areas might be at higher risk for an unhealthy life style, so that may be pertinent analyzing and comparing differences in these areas. ${ }^{2,7}$

In addition, rising knowledge about health -related behaviors and perceived QoL in childhood and adolescence is especially relevant for public health and nursing care, in order to promote health on different settings and environments, because quality of life at this development phase lays the foundation for health and quality of life in adulthood. ${ }^{1}$

The aim of the present study was to examine cross-cultural differences in adolescent perceived QoL and health-related behaviors, on adolescents from the south Portugal and the south of Spain. This study aimed at contributing to the identification of similarities and differences between these Portuguese and Spanish adolescents regarding health and well-being, in order to inform and to improve health prevention policies and practice. 


\section{METHOD}

\section{Participants}

An observational, transversal study was carried out with Portuguese and Spanish adolescents between 15 and 17 years attending public schools from Faro and Seville, which are, respectively, the capital cities of the Southern regions of Portugal (Algarve) and of Spain (Andalusia).

The sample size was calculated with GPower software vs. 3.1.5. We estimated a sample size of 210 participants ( 105 by country) in order to be able to identify differences between two independent means of two tails at $\alpha<.05$ significance level with a power $80 \% 1-\beta$ if effect size was medium $(\mathrm{d}=.50)$. We used a 1.5 inflation factor for cluster design effect, so the final estimated sample size was 315 participants.

Finally, we selected a sample of 319 adolescents (158 Portuguese and 161 Spanish) by cluster randomized (class group as randomized unit).

\section{Measures}

We have used two instruments in order to evaluate both QoL and health related behaviors in adolescents, previously validated for Portuguese and Spanish adolescent populations.

Quality of life: the Kidscreen-27 child selfreport was used. This measure is aimed for the evaluation of perceived QoL in children and adolescents, aged between 8 and $18 .{ }^{11-13}$ It consists of 27 items to be rated on a scale from 1 (not at all/poor) to 5 (extremely/ excellent) and has five subscales: Health and Physical Well-Being (e.g., "Have you felt fit and well"), Psychological Well-Being (e.g., "Has your life been enjoyable?"), Parent Relations \& Autonomy (e.g., "Have your parent(s) treated you fairly?"), Social Support \& Peers (e.g., "Have you spent time with your friends?") and School Environment (e.g., "Have you been able to pay attention?"). The General QoL Index score can be obtained by the sum of all items. Higher scores indicate better HRQoL and well-being. In our study the Cronbach's alpha was $.83\left(\mathrm{a}_{\mathrm{PT}}=.81, \mathrm{a}_{\mathrm{SP}}=.82\right)$ for the total quality of life score, $.60\left(\mathrm{a}_{\mathrm{PT}}=.59, \mathrm{a}_{\mathrm{SP}}=.62\right)$ for Health and Physical Well-Being, .75 $\left(\mathrm{a}_{\mathrm{PT}}=.77\right.$, $\left.\mathrm{a}_{\mathrm{SP}}=.72\right)$ for Psychological Well-Being, $.84\left(\mathrm{a}_{\mathrm{PT}}=.86\right.$, $\left.\mathrm{a}_{\mathrm{SP}}=.74\right)$ for Autonomy \& Parent Relation, .81 $\left(\mathrm{a}_{\mathrm{PT}}=.85, \mathrm{a}_{\mathrm{SP}}=.71\right)$ for Social Support \& Peers and $.76\left(\mathrm{a}_{\mathrm{PT}}=.70, \mathrm{a}_{\mathrm{SP}}=.73\right)$ for School Environment.

Health Behavior in School-aged Children (HBSC) Questionnaire: to evaluate healthy life styles and behaviours towards health reported by adolescents, a short version of the HBSC questionnaire was used. ${ }^{9,14-16}$ This survey was conceived to assess well-being and health-related risk behaviors in children according to the guidelines of the World Health Organization Collaborative Cross-National Study. ${ }^{2}$ It includes items about eating habits, body image, physical activity practice, free-time activities, substance use (hashish, heroin, cocaine, ecstasy, solvents, smoking, and alcohol consumption), violence/bulling, peers, school environment, positive health, sexual behaviors, and family indicators. The adolescent must report a list of health-related behaviors and the frequency he or her engaged in these daily, weekly, etc. (for instance, in the sexual behavior scale: "how old were you when you had your first sexual intercourse?", or "last time you had sexual intercourse, which method you or your partner used to prevent pregnancy?).

In the present study adolescents were questioned about substance use (legal and illegal substances), and first sexual intercourse age. Participants were asked whether they had ever taken tobacco, cannabis and other legal and illegal drugs in their life. Also how often they drink anything alcoholic and were given a list of drinks: beer, wine, liquor (response options ranged from $1=$ "never" to $5=$ "every day"), as whether they had ever had so much alcohol that they were "really drunk" (response options ranged from $1=$ "no, never" to $4=$ "yes, more than 10 times").

Socio-demographic variables: the following data was collected - Adolescent's age and gender and mother's and father's academic qualifications.

\section{Procedure}

In both Portugal and Spain, school boards were contacted and agreed to participate. Informed consent form of parents and adolescents was requested. Participation was voluntary. Instruments were filled in classroom context and one trained interviewer was present in order to answer any questions concerning the questionnaires.

\section{Statistical analysis}

Missing data on the item level were extrapolated using the missing value analysis of SPSS. If more than $10 \%$ of the items of a questionnaire were missing, it was removed from the analyses. Statistical assumptions for parametric analyses were checked with satisfactory results. ${ }^{17}$ 
Descriptive statistics by country were computed for the variables in study. To compare categorical variables we used $\chi^{2}$ (chi-square) test and ANOVA to compare means between groups. Statistical analyses were performed with SPSS software vs. 18.

In Spain, study has been approved by the Ethics Committee of Experimentation of University of Seville with date of April 30 ${ }^{\text {th }}, 2010$. In Portugal, it has been approved by the Ministry of Education (ref.: 008970001).
The mean age of the Portuguese adolescents was $15.77(\mathrm{SD} \pm .77)$, with $49.40 \%(\mathrm{n}=78)$ of girls and $50.60 \%(n=80)$ of boys. The mean age of the Spanish adolescents was $15.61(\mathrm{SD}=.71)$, and $46 \%$ $(\mathrm{n}=87)$ were girls and $54 \%(\mathrm{n}=74)$ were boys. Spanish and Portuguese adolescents were comparable regarding age $[\mathrm{F}(1,317)=3.59, \mathrm{p}=0.59]$ and gender $\left[\chi^{2}(1, n=319)=.697, \mathrm{p}=.404\right]$.

Results suggest significant differences between Portuguese and Spanish adolescents in health-related behaviors and quality of life. These comparisons are presented in tables 1 and 2.

\section{RESULTS}

Table 1 - Differences according to country, in smoking, illegal and legal drugs. Faro, Portugal; Seville, Spain 2011

\begin{tabular}{lccrc}
\hline & Portugal $\mathbf{( n = 1 5 5 )}$ & Spain $(\mathbf{n}=\mathbf{5 1})$ & $\left.\chi^{\mathbf{2}} \mathbf{( d f}, \mathbf{n}\right)$ & P \\
\cline { 2 - 5 } Smoking & $26.5 \%$ & $45.7 \%$ & $12.13(1,306)$ & .000 \\
Hashish & $16.6 \%$ & $20.5 \%$ & $0.79(1,301)$ & .374 \\
Legal drugs & $12.7 \%$ & $1.3 \%$ & $14.80(1,300)$ & .000 \\
\hline
\end{tabular}

More Portuguese adolescents experimented legal drugs to be more calm or active $(12.7 \%)$ than Spanish $(1.3 \%)\left(\chi^{2}(1)=14.80, p=.000\right)$, although a greater percentage of Spanish adolescents smokes $(45.7 \%)\left(\chi^{2}(1)=12.13, p=.000\right)$ (Table 1$)$.
Also Portuguese adolescents consume more wine $\left(\mathrm{F}(1,299)=19.68, \mathrm{p}=.000, \eta^{2}=.06\right)$ and beer $\left(\mathrm{F}(1,304)=74.85, \mathrm{p}=.000, \eta^{2}=20\right)$ than Spanish adolescents, with a small magnitude size-effect (Table 2).

Table 2 - Differences according to country in health-behaviors and quality of life. Faro, Portugal; Seville, Spain 2011

\begin{tabular}{lccccc}
\hline & Portugal & Spain & & & \\
\cline { 2 - 6 } & $\mathbf{M}(\mathbf{S D})$ & $\mathbf{M}(\mathbf{S D})$ & $\mathbf{F ~ ( d f , ~} \mathbf{n})$ & $\mathbf{P}$ & $\eta^{\mathbf{2}}$ \\
\hline $1^{\text {st }}$ sexual intercourse age & $14.31(1.44)$ & $14.70(0.99)$ & $2.57(1,123)$ & .112 & .02 \\
Beer consumption & $2.31(1.23)$ & $1.32(0.68)$ & $74.85(1,304)$ & .000 & .20 \\
Wine consumption & $1.62(0.28)$ & $1.25(0.53)$ & $19.68(1,299)$ & .000 & .06 \\
Liquor consumption & $2.30(1.19)$ & $2.40(1.06)$ & $0.64(1,304)$ & .424 & .00 \\
Inebriation & $2.60(1.56)$ & $2.40(1.57)$ & $1.29(1,306)$ & .257 & .00 \\
Physical well-being & $3.42(0.76)$ & $3.71(0.80)$ & $10.44(1,306)$ & .001 & .03 \\
Psychological well-being & $3.82(0.69)$ & $4.09(0.57)$ & $14.17(1,306)$ & .000 & .04 \\
Family & $3.80(0.74)$ & $4.15(0.65)$ & $19.94(1,306)$ & .000 & .06 \\
Peers and social support & $4.11(0.84)$ & $4.42(0.57)$ & $13.49(1,306)$ & .000 & .04 \\
School environment & $3.37(0.70)$ & $3.96(0.64)$ & $59.38(1,306)$ & .000 & .16 \\
Total quality of life & $3.70(0.54)$ & $4.07(0.45)$ & $40.83(1,306)$ & .000 & .12 \\
\hline
\end{tabular}

None of the adolescents in our sample experimented heroin and the majority had never experimented cocaine $(99.7 \%)$, ecstasy $(98 \%)$, solvents $(99.3 \%)$, or other illegal drugs $(98.4 \%)$, and we found no significant differences between the two countries on substance use. Also, we found no differences between the countries on hashish use (Table 1). Alcohol was the substance more frequently consumed by our participants: $140(43.9 \%)$ had consumed beer, 96 (30.0) had consumed wine, 224 (70.3) had consumed liquor and 164 (51.4) had already been drunk. Significant differences were 
found on beer and wine consumption between the Spanish and the Portuguese adolescents, but not on liquor consumption and inebriation. Also, no significant differences were found between the two countries on the age of the first sexual intercourse (Table 2).

We observed significant differences between Portuguese and Spanish in all the dimensions of quality of life (Table 2). The average scores observed in the Spanish sample are significantly higher, suggesting that Spanish adolescents perceived themselves with better quality of life when compared to the Portuguese adolescents. These differences had a medium-effect size in School environment and total Quality of life.

In table 3 and 4 we present the results of the comparison of the average scores obtained in each of the variables studied by country according to gender. Results suggested significant differences in gender between countries.

Table 3 - Differences according to country in smoking, illegal and legal drugs consumption. Faro, Portugal; Seville, Spain 2011

\begin{tabular}{|c|c|c|c|c|c|c|}
\hline & \multicolumn{3}{|c|}{ Portugal } & \multicolumn{3}{|c|}{ Spain } \\
\hline & $\begin{array}{c}\text { Boys } \\
\mathbf{n}=77 \text { ) }\end{array}$ & $\begin{array}{c}\text { Girls } \\
(\mathrm{n}=78)\end{array}$ & $\chi^{2}(\mathrm{df}, \mathbf{n})$ & $\begin{array}{c}\text { Boys } \\
(n=4)\end{array}$ & $\begin{array}{c}\text { Girls } \\
(\mathrm{n}=77)\end{array}$ & $X^{2}(\mathrm{df}, \mathrm{n})$ \\
\hline Smoking & $23 \%$ & $30 \%$ & $0.744(1,155)$ & $42 \%$ & $49 \%$ & $0.846(1,151)$ \\
\hline Hashish & $20 \%$ & $13 \%$ & $1.279(1,151)$ & $23 \%$ & $18 \%$ & $0.531(1,151)$ \\
\hline Legal drugs & $8 \%$ & $17 \%$ & $2.744(1,150)^{*}$ & $0 \%$ & $3 \%$ & $t$ \\
\hline
\end{tabular}

${ }^{*} \mathrm{p}<.10, \uparrow 50 \%$ of cells had expected count less than 5 . We used the Fisher 's exact test $\mathrm{p}=.140$.

We have found the following significant differences between boys and girls from the Portuguese sample: girls started their first sexual intercourse later $\left(\mathrm{F}(1,77)=5.07, \mathrm{p}=.027, \eta^{2}=.06\right)$, and consume less beer than boys $\left(\mathrm{F}(1,153)=8.62, \mathrm{p}=.004, \eta^{2}=.05\right)$, although these differences have a small magnitude. Also, in the Portuguese sample, we observed a trend to girls to report having experimented legal drugs in order to be more calm or active, in other words, suggesting a misuse of legal drugs on this subgroup $\left(\chi^{2}(1)=2.74, p=.098\right)$. Referring to quality of life, we have observed that Portuguese girls only scored significantly lower than boys in the Physical Wellbeing dimension $\left(\mathrm{F}(1,155)=4.37, \mathrm{p}=.000, \eta^{2}=.09\right)$, with a medium size-effect.
We have found more significant differences between boys and girls on the quality of life dimensions in Spanish adolescents, when compared to Portuguese. However, no significant differences were found on age of first sexual intercourse, tobacco, alcohol and illegal drugs consumption between Spanish boys and girls. Regarding quality of life dimensions, Spanish girls scored significantly lower than Spanish boys in the Physical Wellbeing dimension $\left(\mathrm{F}(1,151)=36.54, \mathrm{p}=.000, \eta^{2}=.20\right)$, Psychological Well-being $(\mathrm{F}(1,151)=11.91, \mathrm{p}=.001$, $\left.\eta^{2}=.07\right)$, and Total Quality of life $(\mathrm{F}(1,151)=9.39$, $\left.\mathrm{p}=.003, \eta^{2}=.06\right)$. These differences did represent a small-sized effect, except for Physical well-being, which represents a medium-size effect.

Table 4 - Mean (and standard deviations) of health-behaviors and quality of life. Comparison according to gender and country. Faro, Portugal; Seville, Spain 2011

\begin{tabular}{|c|c|c|c|c|c|c|c|c|}
\hline & \multicolumn{4}{|c|}{ Portugal } & \multicolumn{4}{|c|}{ Spain } \\
\hline & $\begin{array}{c}\text { Boys } \\
(\mathrm{n}=77)\end{array}$ & $\begin{array}{c}\text { Girls } \\
(n=78)\end{array}$ & & & $\begin{array}{c}\text { Boys } \\
(\mathrm{n}=74)\end{array}$ & $\begin{array}{c}\text { Girls } \\
(\mathrm{n}=77)\end{array}$ & & \\
\hline & M(DP) & M(DP) & $\mathrm{F}(\mathrm{df}, \mathrm{n})$ & $\eta^{2}$ & M(DP) & M(DP) & $F(d f, n)$ & $\eta^{2}$ \\
\hline $1^{\text {st }}$ sexual intercourse age & $\begin{array}{l}13.98 \\
(1.60)\end{array}$ & $\begin{array}{l}14.69 \\
(1.12)\end{array}$ & $\begin{array}{c}5.07 \\
(1,77)^{*}\end{array}$ & .06 & $\begin{array}{l}14.79 \\
(0.90)\end{array}$ & $\begin{array}{l}14.53 \\
(1.12)\end{array}$ & $\begin{array}{l}0.763 \\
(1,46)\end{array}$ & .02 \\
\hline Beer consumption & $\begin{array}{c}2.60 \\
(1.25)\end{array}$ & $\begin{array}{c}2.03 \\
(1.15)\end{array}$ & $\begin{array}{c}8.62 \\
(1,153) \dagger\end{array}$ & .05 & $\begin{array}{c}1.43 \\
(0.80)\end{array}$ & $\begin{array}{c}1.22 \\
(0.53)\end{array}$ & $\begin{array}{c}3.74 \\
(1,151)\end{array}$ & .02 \\
\hline Wine consumption & $\begin{array}{c}1.74 \\
(0.91)\end{array}$ & $\begin{array}{c}1.5 \\
(0.82)\end{array}$ & $\begin{array}{c}2.83 \\
(1,149)\end{array}$ & .02 & $\begin{array}{c}1.30 \\
(0.61)\end{array}$ & $\begin{array}{c}1.20 \\
(0.43)\end{array}$ & $\begin{array}{c}1.34 \\
(1,150)\end{array}$ & .01 \\
\hline
\end{tabular}


Lima-Serrano M, Lemos I, Nunes C

\begin{tabular}{lcccccccc}
\hline Liquor consumption & 2.27 & 2.32 & 0.08 & & 2.28 & 2.51 & 1.68 & \\
& $(1.18)$ & $(1.20)$ & $(1,153)$ & .00 & $(1.04)$ & $(1.07)$ & $(1,151)$ & .01 \\
Inebriation & 2.62 & 2.58 & 0.03 & & 2.38 & 2.42 & 0.02 & \\
& $(1.52)$ & $(1.60)$ & $(1,155)$ & .00 & $(1.53)$ & $(1.61)$ & $(1,151)$ & .00 \\
Physical well-being & 3.65 & 3.20 & 14.37 & .09 & 4.08 & 3.37 & 36.54 & .20 \\
& $(0.84)$ & $(0.61)$ & $(1,155) \ddagger$ & & $(0.66)$ & $(0.77)$ & $(1,151) \ddagger$ & \\
Psychological well-being & 3.84 & 3.79 & 0.24 & .00 & 4.25 & 3.94 & 11.91 & .07 \\
& $(0.76)$ & $(0.62)$ & $(1,155)$ & & $(0.48)$ & $(0.61)$ & $(1,151) \dagger$ & \\
Family & 3.90 & 3.69 & 3.20 & .02 & 4.23 & 4.08 & 1.89 & .01 \\
& $(0.68)$ & $(0.78)$ & $(1,155)$ & & $(0.65)$ & $(0.64)$ & $(1,151)$ & \\
Peers and Social Support & 4.08 & 4.15 & 0.24 & .00 & 4.44 & 4.40 & 0.18 & .00 \\
& $(0.89)$ & $(0.79)$ & $(1,155)$ & & $(0.50)$ & $(0.63)$ & $(1,151)$ & \\
School environment & 3.37 & 3.37 & 0.00 & .00 & 3.90 & 4.01 & 1.14 & .01 \\
& $(0.75)$ & $(0.64)$ & $(1,155)$ & & $(0.70)$ & $(0.57)$ & $(1,151)$ & \\
Total quality of life & 3.767 & 3.64 & 2.29 & .01 & 4.18 & 3.96 & 9.39 & .06 \\
\hline
\end{tabular}

${ }^{*} \mathrm{p}<.05 ; \uparrow \mathrm{p}<.01 ; \neq \mathrm{p}<.001$.

\section{DISCUSSION}

This cross-cultural study examined differences in perceived QoL and health-related behaviors, as well as the impact of gender in QoL and in health-behaviors on southern Spanish and Portuguese adolescents. The results suggested significant differences between Portuguese and Spanish adolescents in a number of the health-related behaviors analyzed. Previous descriptive studies with adolescent samples both in Portugal and in Spain have also found differences between perceived QoL, health-related behaviors and individual variables such as gender and age. However, no comparisons were made between the two countries on these studies. ${ }^{2,12}$

Because of sexual intercourse in adolescent may be linked to health related problems, such as, sexually transmitted infections (STIs), unwanted pregnancy, abortion and negative psychosocial health, it is pertinent to conceive strategies that may help to delay the first sexual intercourse ${ }^{2}$. In the present work significant differences were not found between both countries on the age of the first sexual intercourse. Also, this was similar to the first sexual intercourse age found in previous studies. ${ }^{9,11}$

According to previous studies, alcohol has been the substance most used in both countries, followed by other legal substances such tobacco (mainly in Spanish adolescents), and legal drugs (mainly in Portuguese girls). Some differences on the use of legal substances have been found between both countries. However, these results are similar of those obtained in previous researches and it indicates a high consumption rate of legal substances among the adolescent population. This results point out the importance of performing health promotion strategies to this target population, in which nurses play an important role. ${ }^{2,9,11,18}$

Despite the need to take into consideration a subgroup of adolescents at increased risk for low QoL, the majority of the participants in our study have reported not having consumed legal or illegal substances. Specifically, none of the adolescents in the Portuguese and Spanish samples have tried heroin, and the majority had never experimented cocaine, solvents, or other illegal drugs, ${ }^{2,9,11}$ and we found no significant differences between the two countries on overall illegal substance use. Results of investigations conducted both in Portugal and in Spain suggest that adolescents that report alcohol and substance abuse during adolescence also report lower health-related QoL significantly higher psychopathological symptoms. ${ }^{19,20}$ As alcohol and substance use in adolescence is related with the youth well-being, ${ }^{19}$ these results suggest that most participants in our study perceive their QoL as fulfilling and gratifying. A further study should address the effect of perceived QoL in substance use, controlling for the country of origin of the adolescents.

Regarding the significant differences among the two countries on health-related behaviors according to gender, Portuguese girls reported initiating sexual intercourse later than Portuguese boys. Also, in this sample, boys reported significantly more beer consumption than girls as pointed out by empirical work..$^{18,21}$ No differences were found between Portuguese boys and girls on report of drug use. In its turn, results of the comparison analyses between Spanish female and male adoles- 
cents indicate no significant differences on the age of the first sexual intercourse, tobacco, alcohol and illegal drugs consumption, allowing us to suggest fewer differences on health-related behaviors due to gender in the Spanish. Despite of the diverse results found on these health-related behaviours, different patterns in health-related QoL due to gender and to other social and cultural specificities should be considered when promoting health and well-being in group interventions.

Regarding health-related Quality of Life, our results suggest that Spanish adolescents perceive themselves with better general QoL (Physical Well-being, Psychological Well-being, Family, Peers and Social Support, and School environment), when compared with Portuguese adolescents. Although we have not found previous studies comparing Spanish and Portuguese adolescents on QoL , Spanish adolescents reported high levels of QoL when were compared with other European countries, such as, France, UK or Greece by KIDSCREEN group. ${ }^{12}$ QoL has been associated with ethnicity and place of residence, among other issues. ${ }^{6}$ A future study should investigate further similarities and differences on the perceptions of QoL between Portuguese and Spanish adolescents, controlling for environmental variables that may be influencing health and well-being.

Results of the comparison of the teenagers on QoL variables according to gender indicated significant differences between boys and girls on the quality of life dimensions, mostly in the Spanish group. Namely, Spanish girls reported lower QoL in Physical Well-being, in Psychological Well-being, and in the Total Quality of Life dimension, when compared to Spanish boys. On the other hand, differences between Portuguese girls and boys were found only for the Physical Well-being dimension, with girls reporting lower than boys on this variable. Studies on the adolescents' health-related QoL generally indicate that boys tend to report higher levels on life satisfaction, when compared to girls. ${ }^{11,22-23}$ This may be due to differences due to gender in the engagement of health-related behaviors, and it may be related to cultural and educational issues that assign different roles to men and women. Nevertheless, we must consider the fact that boys and girls tend to differ in the perception of these dimensions, which may be related to a higher vulnerability of female adolescents to express problems associated with internalizing disorders, such as anxiety, depression and interpersonal problems. ${ }^{24}$
In the present study we tried to eliminate biases due to the cross-cultural comparability of the measurements by means of internationally used and validated questionnaires. Nevertheless, data representativeness of our study is weak due to the small sample sizes and they just collected from southern capitals of both countries, Spain and Portugal. Also, because of changes in QoL from the beginning to the end of adolescence period it may be beneficial to compare similarities and differences between Spanish and Portuguese adolescents according to age, therefore, comprehending 12 to 18 year sample groups. One last limitation concerns the sources of information. Because the variables were assessed solely from the point of view of the teenager it would be important to consider other information sources, such as peers and parents.

\section{CONCLUSIONS}

Overall, the results of the present study suggest that alcohol and substance abuse during adolescence is related with lower health-related QoL and a higher report of psychopathological symptoms in the adolescents. Furthermore, most participants from both countries tend to perceive their health-related behaviors and QoL fulfilling and gratifying, as pointed out by several epidemiological studies with adolescents from western countries. Learning about the health-related behaviors and perceived QoL in adolescence is especially relevant for practical nursing when promoting health of adolescents in different settings and contexts, such as schools, which become suitable and accessible places where nurses might carry out health promotion strategies. A future study should consider including the assessment of specific psychopathological problems in association with either, overall health-related quality of life and engagement in health-related behaviors.

\section{ACKNOWLEDGEMENTS}

The Portuguese study was partially financed by Fundação para a Ciência e Tecnologia of Portugal.

\section{REFERENCES}

1. Ramos P, Moreno C, Rivera F, Pérez PJ. Integrated analysis of the health and social inequalities of Spanish adolescents. International Int J Clin Health Psychol. 2010 Sep; 10(3):477-98.

2. Currie C, Zanotti C, Morgan A, Currie D, De Looze M, Roberts C, et al. editors. Social determinants of health and well-being among young people. 
Health behaviour in school-aged children (HBSC) study. International report from the 2009/2010 survey. Health policy for children and adolescents, no.6. Copenhagen: WHO Regional Office for Europe, 2012 [acess 2012 May 4]. Disponible en: http://www.euro.who.int/__data/assets/pdf_ file/0003/163857/Social-determinants-of-healthand-well-being-among-young-people.pdf

3. Aparecida R, Trench ME. The university as a place that promotes quality of life: perceptions and experiences of nursing students. Texto Contexto Enferm. 2006 Apr-Jun; 15(2):254-61.

4. Schwartzmann L. Health-related Quality of Life: conceptual aspects. Cienc Enferm. 2003 Dec, 9(2):9-21.

5. Gaspar T, Gaspar M, Pais R, José L, Leal I, Ferreira A. Health-related quality of life in children and adolescents and associated psychosocial factors. J Cogn Behav Psychother. 2009 Mar; 9(1):33-48.

6. Giannakopoulos G, Dimitrakaki C, Xanthi P, Kolaitis G, Rotsika V, Ravens-Sieberer U, et al. Adolescents' wellbeing and functioning: relationships with parents'subjective general physical and mental health. Health Qual Life Outcomes. 2009 Dec; 7:100.

7. Lahana E, Pappa E, Niakas D. The impact of ethnicity, place of residence and socioeconomic status on heath-related quality of life: results from Greek health survey. Int J Public Health. 2010 Oct; 55(5):391-400.

8. Ravens-Sieberer U, Auquier P, Erhart M, Gosch A, Rajmil L, Bruil J, et al. The KIDSCREEN-27 quality of life measure for children and adolescents: psychometric results from a cross-cultural survey in 13 European countries. Qual Life Res. 2007 Oct; 16(8):1347-56.

9. Moreno C, Muñoz-Tinoco V, Pérez PJ, SánchezQueija I, Granado MC, Ramos P, et al. Desarrollo adolescente y salud. Resultados del estudio HBSC2006 con chicos y chicas españoles de 11 a 17 años. A World Health Organization crossnational study. Madrid (ES): Ministerio de Sanidad y Consumo; 2006.

10. Gaspar M, Simões C, Tomé G, Camacho I, Ferreira M, Ramiro L, et al. Aventura social \& saúde. Saúde das adolescentes portugueses. Relatório de Estudo HBSC 2010. Lisboa (PT): MS; 2010.

11. Matos MG, Gaspar T, Ferreira M, Linhares F, Simões C, Diniz, et al. Qualidade de Vida em crianças e adolescentes - projecto europeu kidscreen, relatório português. Lisboa (PT): Projecto Aventura Social \& Saúde, Faculdade de Motricidade Humana; 2006.

12. Ravens-Sieberer U, Schmidt S, Gosch A, Erhart $\mathrm{M}$, Petersen $\mathrm{C}$, Bullinger $\mathrm{M}$. Measuring subjective health in children and adolescents: results of the European kidscreen/Disabkids Project. Psychosoc Med. 2007 Jul; 4(8):1-13.

13. Robitail S, Ravens-Sieberer U, Simeoni M, Rajmil $\mathrm{L}$, Bruil J, Power M. et al. Testing the structural and cross-cultural validity of the KIDSCREEN-27 quality of life questionnaire. Qual Life Res. 2007 Oct; 16:1335-45.

14. Currie CE, Elton RA, Todd J, Platt S. Indicators of socioeconomic status for adolescents: the WHO Health Behaviour in School-aged Children Survey. Health Educ Res. 1997 Sep; 12:385-97.

15. Currie, CE. Health behaviour in school-aged children. Research protocol for the 1997-98 survey. A World Health Organization Cross-National Study. Edinburgh: University of Edinburgh; 1998.

16. Matos MG, equipa do Projecto Aventura Social \& Saúde. A saúde dos adolescentes portugueses (Quatro anos depois). Lisboa (PT):Edições FMH; 2003.

17. Field A. Discovering statistics using SPSS. $3^{\text {a }}$ ed. London (UK): Sage; 2009.

18. Fonseca H. Compreender os adolescentes: um desafio para pais e educadores. Lisboa (PT): Editorial Presença; 2002.

19. Matos MG, Gaspar T, Vitória P, Clemente MP. Comportamentos e atitudes sobre o tabaco em adolescentes portugueses fumadores. Psicol Saúde Doenças. 2003 Nov; 4(2):205-19.

20. Diez JP, Peirats EB. Análisis de los estilos parentales de socialización asociados al abuso de alcohol en adolescentes. Psicothema. 1997, 9(3):609-17.

21. Bisegger C, Cloetta B, Von Rueden U, Abel T, Ravens-Sieberer U. The European Kidscreen Group. Health-related quality of life: gender differences in childhood and adolescence. Soz Praventivmed. 2005 [access 2013 Mar 13] Sep; 50(5): 281-91. Available from: 10.1007 / s00038-005-4094-2

22. Matos MG. A Saúde do Adolescente: O que se sabe e quais são os novos desafios? Análise Psicológica. 2008 Apr; 26(2):251-63.

23. Tebea C, Berra S, Herdman M, Aymericha M, Alonso J, Rajmila L. Fiabilidad y validez de la versión española del KIDSCREEN-52 para población infantil y adolescente. Med Clin (Barc). 2008 Nov; 130(17):650-4.

24. Lemos IT, Faísca LM, Valadas ST. Assessment of psychopathological problems in the context: the psychometric properties of a portuguese version of the adolescent psychopathology scale-short form. J Psychoeduc Assess. 2011 Feb; 29(1):63-74. 